\title{
Many eligible federal inmates won't get new hepatitis treatment
}

$\mathrm{F}$ aced with a huge increase in the number of inmates with hepatitis $\mathrm{C}$ virus $(\mathrm{HCV})$ infection eligible for treatment with new, more easily tolerated drugs, Correctional Service Canada (CSC) has decided to add 50 patients to its current target of 240 in treatment annually - a figure that outside analysts say could exclude as many as 1700 eligible patients from treatment.

"Although CSC would prefer to treat everyone, the cost of the drugs makes this impossible," CSC spokeswoman Lori Halfper explained in a statement to $C M A J$. "Therefore, triage is the necessary professional approach. Each region within CSC manages demand for access to $\mathrm{HCV}$ medications in the context of funding all other health services at the same time."

Some of the new direct-acting antiviral therapies cost up to $\$ 60000$ for the full treatment.

Hepatitis specialists describe CSC's decision to exclude large numbers of patients as a public health setback. "Many of these folk will only come into contact with health care when they are in prison," says Dr. Peter Ford, a specialist in HIV and HCV care in federal prisons. "CSC is in a unique position of potentially being able to treat the people that otherwise will slip through the net." Ford says, "CSC needs to be making a pitch for extra funding on this basis."

Adam Cook, a hepatitis policy researcher with the Toronto-based Canadian Treatment Action Council is encouraged by the increase in treatment, but says it is "still just a drop in the bucket. We're not even getting ahead of new infections with this approach." $\mathrm{He}$ says the CSC lacks leadership and is "late to the game."

Some experts contend that if CSC implemented national treatment guidelines, the number of eligible inmates could be as high as 2000. CSC's director general of clinical services and public health, Henry De Souza, acknowledges that the number of patients eligible for

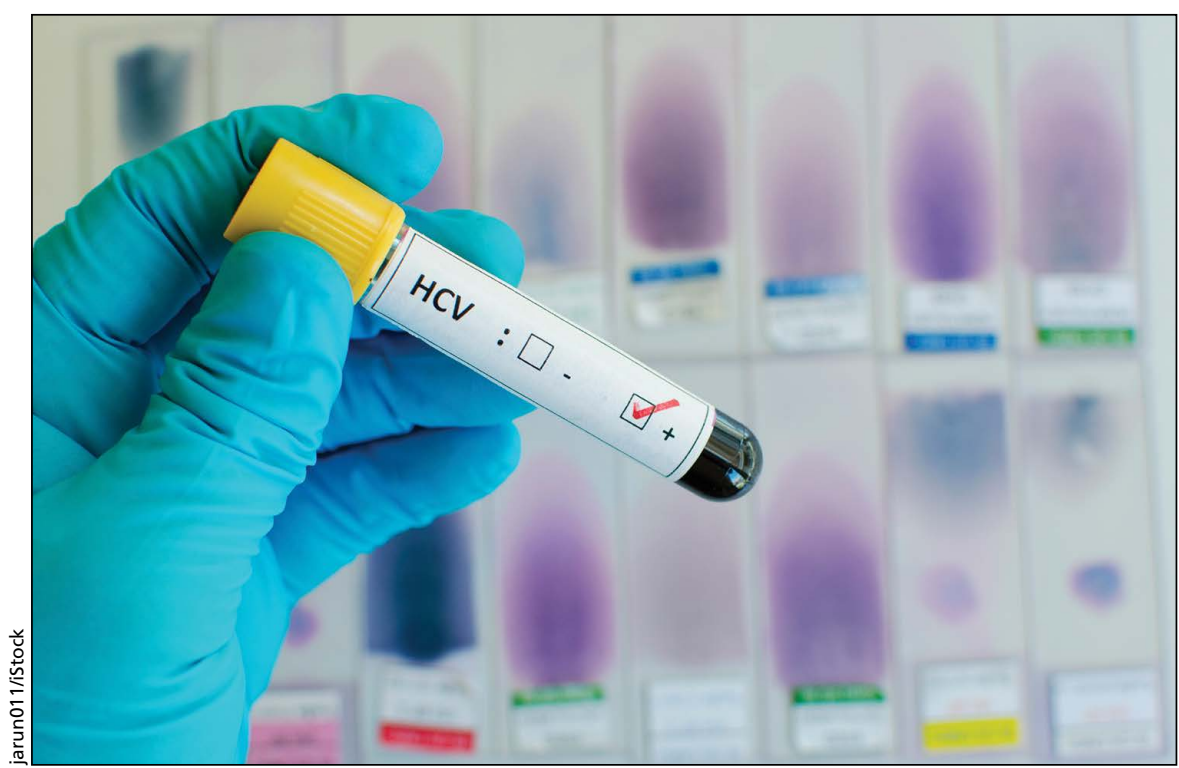

Experts estimate that as many as $\mathbf{2 0 0 0}$ federal inmates are eligible for new, more easily tolerated treatment for hepatitis $C$.

treatment is far larger than the 290 who will receive it. But he says that "not every individual who has the antibody requires treatment. Of those who require treatment, not all of them require treatment immediately, so there is a process in terms of individuals and the decision by their physicians to treat them."

"Our estimate is that by the end of 2013, there were about 668 inmates in Ontario who had antibodies to HCV, but not all of these would have active $\mathrm{HCV}$ infections or meet the criteria for treatment," De Souza said. Ontario is home to roughly one-third of CSC's 15000 inmates across Canada.

De Souza also disagreed with the claim from Halfper that financial concerns necessitated "triage" to reduce the number of inmates in treatment. "CSC has never suggested that cost containment was a factor in limiting treatment," De Souza said. "The additional costs for the new treatments may be up to $\$ 15$ million annually," he acknowledged. "CSC is currently assessing options to address this financial pressure. CSC will be able to cover the health care costs for federal inmates."

In selecting the patients who will receive care, De Souza said "the recommendation was that you would want to proceed by prioritizing fibrosis levels 3 and 4 [the most advanced stages of liver damage]." This strategy was adopted by the federal Bureau of Prisons in the US.

Legal analysts warn that capping the number of inmates in treatment is potentially problematic. "On its face, it seems to infringe on the internationally recognized human rights standard of equivalence of care between corrections and community," says CTAC lawyer Glenn Betteridge.

"The cap may also raise constitutional concerns," Betteridge adds. "At least three courts in the US have certified prisoner class actions against prison authorities, alleging deliberate indifference amounting to cruel and unusual punishment because prison authorities have dragged their feet and not provided treatment to prisoners with Hep C." - Paul Webster, Toronto, Ont. 